\title{
Assessment Of Water Quality And Bottom Supplies In The Bottom Of The Mekong River
}

\author{
Glazunova Irina Viktorovna', Karpenko Nina Petrovna², Nguyen Thi Thuy Nhung ${ }^{3}$, Natalia V. \\ Lagutina $^{4}$, Barsukova Maria Vasilievna ${ }^{5}$
}

${ }^{1}$ candidate of technical Sciences, associate Professor of the «Department of integrated water resources management and hydraulics»,FSBEI HE RGAU-MSHA named after C.A. Timiryazev; 127550, Moscow, Pryanishnikova str., 19,tel.8(499)976-21-56

${ }^{2}$ doctor of technical Sciences, head of the department «Hydrology, hydrogeology and flow regulation»FSBEI HE RGAU-MSHA named after C.A. Timiryazev; 127550, Moscow, Pryanishnikova str., 19. tel.: 8(916)069-75-12

${ }^{3}$ student of the «Department of integrated water resources management and hydraulics», FSBEI HE RGAUMSHA named after C.A. Timiryazev; 127550, Moscow, Pryanishnikova str., 19.tel. 8 (964) 7798357; e-mail:

${ }^{4}$ candidate of technical Sciences, associate Professor, Department of environmental safety and environmental management, 8-916-551-32-07

${ }^{5}$ senior lecturer, Department of environmental safety and environmental management 8-917-546-33-02

1'ivglazunova@mail.ru, ${ }^{2}$ npkarpenko@yandex.ru, ${ }^{3}$ thuynhung20996@ gmail.com, ${ }^{4}$ Lag@ @ rambler.ru,

5 gribovaa@ rambler.ru

Article History: Received: 11 January 2021; Accepted: 27 February 2021; Published online: 5 April 2021

\begin{abstract}
The article presents the results of studies of the content of heavy metals in bottom sediments in the lower reaches of the Mekong River ( 3 estuaries in Ben Tre). The results of the content of heavy metals for 20 research sites were analyzed and compared with the national standards of Vietnam, which are used to assess the level of adverse effects on aquatic animals and river ecosystems, as well as with similar standards adopted in various countries of the world. When compared with the standards, the content of heavy metals in the study area (Ben Tre province) was quite high. The tributaries flowing into the main river also have a relatively high content of heavy metals, which proves that, in addition to pollution from the upper reaches of the river, socio-economic activities in the catchment, including land reclamation, also have a strong effect on the accumulation of heavy metals in channel sediments. In addition, the authors, comparing the content of heavy metals, both with the established standards of Vietnam and with the standards of some countries of the world, creating a basis for rational agriculture and sustainable development.
\end{abstract}

Keywords: heavy metal content, channel sediments, quality standards, lower course of the Mekong River

\section{Introduction}

The length of the Mekong River is about $4880 \mathrm{~km}$, the annual volume of river flow is 475 million $\mathrm{m}^{3} / \mathrm{year}$. The Mekong River originates in China, flows through Laos, Myanmar, Thailand, Cambodia and further into the East Sea. The Mekong River divides into two parallel branches: the Tien River and the Hau River, about $230 \mathrm{~km}$ long from the Vietnamese-Cambodian border to the East Sea. Before the rivers flow into the sea, a large delta-shaped plain with 9 river mouths was formed, including 3 mouths in Ben Tre province.

Estuaries and coastal areas are often sites of accumulation of pollutants and heavy metals that come from higher areas. The Mekong River, with a large basin area of 795,000 $\mathrm{km}^{2}$, flows through many agricultural, industrial and residential areas. Thus, the annual amount of heavy metals transported by the water flow downstream and accumulating in bottom sediments in estuaries is relatively high, and the probability of their penetration into ecosystems is very high. Aware of the dangers that heavy metals pose to people living in the basin, many studies have been conducted, including: Pham Thi Nga, Le Van Duc, Nguyen Duy Duyen and Le Viet Thanh (2009) [6]; Nguyen Van Khan and Pham Van Heep (2012) [8]. Studies of the components of heavy metals present in water and bottom sediments were of interest to domestic and foreign scientists, but the results of studying the bottom sediments of the Mekong River still do not give a complete picture and further studies are required, some of which were carried out by the authors..

The Mekong Delta has a tropical monsoon climate with high annual rainfall causing the topsoil to wash away; To replenish the fertility of the land, people in this part of the river basin often use sediments to fill them directly into their gardens. This exercise in the past has been effective at replenishing fertility and high yields, but more recently, in some orchards, such as cocoa and grapefruit, the leaves turned yellow and trees died en masse after the introduction of sediments of the Mekong River into the soil. This phenomenon is explained by the fact that people used bottom sediments contaminated with heavy metals to apply to the soil directly under trees, while these plants were resistant only to very low levels of heavy metals. For the safe use of bottom sediments of the Mekong River for fertilizing washed away erosive soils, it is relevant to study the content of heavy metals in channel sediments in the lower reaches of the river. 
The study examined three estuaries in the lower reaches (delta) of the Mekong River (Ben Tre). The research focused on the analysis of heavy metal concentrations in bottom sediments of the research area. In addition, the content of heavy metals was also compared with the standards adopted in Vietnam and in some countries of the world in order to rationalize the use of river resources in agriculture and ensure sustainable development in the region.

\section{Research methods and results.}

The object of research is the quality of bottom sediments in the lower reaches of the Mekong River in Vietnam (Ben Tre).

The content of heavy metals in the samples was determined using an atomic absorption spectrometer (model: ZEEnit 700_Manufacturer: Analytik Jena - Germany) with instructions and the WinAAS Ver. The rest of the indicators were analyzed according to the data of Savichev O. G. The determination error was about $0.2 \mu \mathrm{g}$, the average value of all replicates during the production of measurements was taken into account).

\section{Results of a field study of water quality and sediment in the lower reaches of the Mekong River}

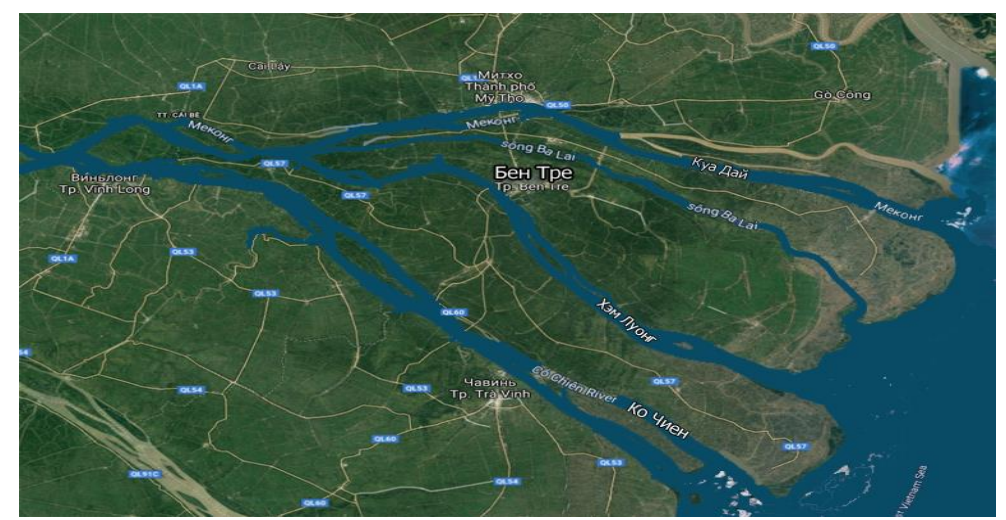

Figure 1: Map of the lower course of the Mekong River (Ben Tre)

The location of sampling points in the lower reaches of the Mekong River is shown in "Figure 2".

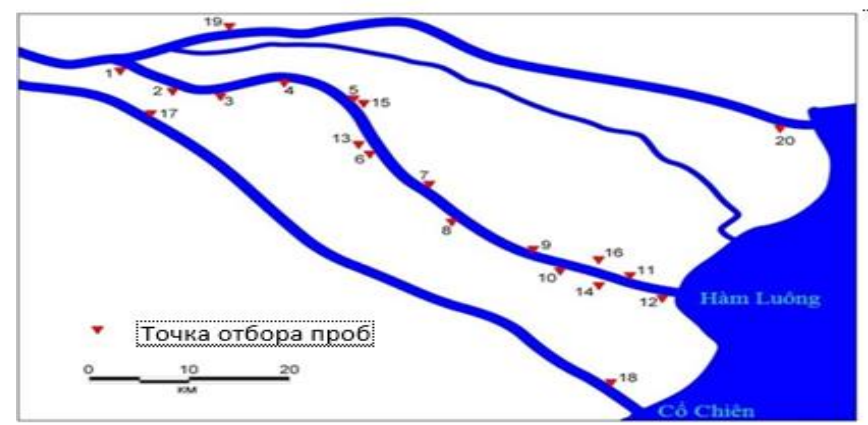

Fig. 2. Location of sediment sampling points in the Lower Mekong (Ben Tre)

The average content of heavy metals in bottom sediments at 20 points of sampling carried out in the Ben-Tre region was revealed in the following order: $\mathrm{Hg}<\mathrm{Cd}<\mathrm{Pb}<\mathrm{As}<\mathrm{Cu}<\mathrm{Zn}$ "Figure $3 "$.

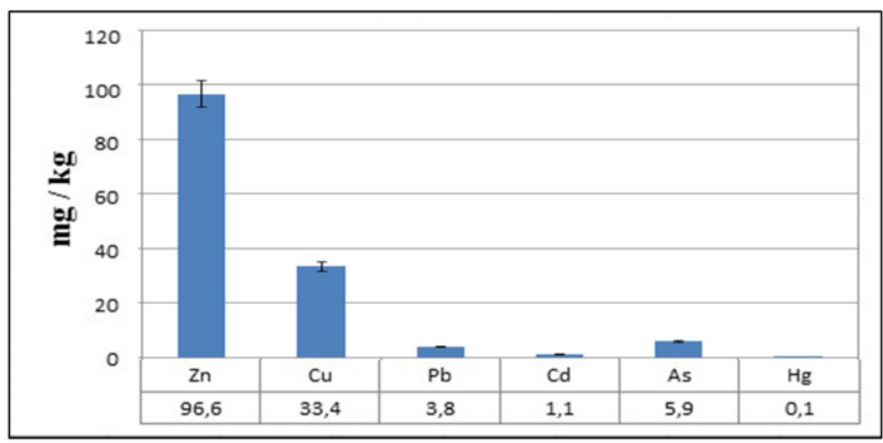

Figure 3. Average heavy metal content in the lower Mekong River [ $\mathrm{mg} / \mathrm{kg}$ dry weight of sediment]

Mining, metallurgy, sewage sludge, coal dust are the reasons leading to the increase in $\mathrm{Zn}$ content in the lower Mekong region. The Mekong Basin has extensive agricultural areas (Thailand and Vietnam are the two countries 
with the largest rice production in the world). The Mekong Delta is known as the "fruit kingdom". The growing use of fertilizers and pesticides is the main factor contributing to the highest $\mathrm{Zn}$ content in river bottom sediments.

In terms of geology, the Mekong River Basin is characterized by lava rocks (Khorat Plateau, Kon-Tum Plateau), where the $\mathrm{Cu}$ content is relatively high. The Mekong River Basin experiences heavy rainfall, high humidity, which leads to the leaching of copper from rocks into streams and its accumulation in bottom sediments at river estuaries, in addition to the production activities of people in the basin. $\mathrm{Cu}$ ranks second in terms of concentration in sediments of bottom sediments in the study area.

Arsenic is found both in bottom sediments of natural origin (arsenic-containing minerals), as it comes from artificial sources (metallurgy and mining). As is abundant in bottom sediments as a result of soil erosion and mining from arsenic-rich rock along the Vietnam-Cambodia border.

Mercury $\mathrm{Hg}$ is found in river bottom sediments as a result of ancient volcanic activity. Along with this, there is a process of industrial production, mining, the development of metallurgy.

Naturally, cadmium $(\mathrm{Cd})$ is widespread in volcanic rocks upstream of the Mekong River. Lead $(\mathrm{Pb})$ forms sulfur compounds, which are abundant in igneous rocks. $\mathrm{Cd}$ and $\mathrm{Pb}$ found in high concentrations in sedimentary and metamorphic rocks of Northern Laos. Currently, the Mekong Delta has relatively developed industrial parks, craft villages, factories that are located along river banks (dyeing fabrics, ceramic enamels, lacquer painting, cement production). Urban areas are being built, as well as treatment facilities, the use of fertilizers, chemicals for plant and animal protection, etc. is increasing. All of the above contributes to an increase in the content of $\mathrm{Cd}$ and $\mathrm{Pb}$. Indicators for heavy metals in the study area are quite high and exceed Vietnamese standards.

Table 1 - Content of some heavy metals in bottom sediments in the lower reaches of the Mekong River (Ben Tre province) $[\mathrm{mg} / \mathrm{kg}$ dry sediment weight $]$

\begin{tabular}{|l|l|l|l|l|l|l|}
\hline & $\mathbf{Z n}$ & $\mathbf{C u}$ & $\mathbf{P b}$ & $\mathbf{C d}$ & $\mathbf{A s}$ & $\mathbf{H g}$ \\
\hline 1 & 96,1 & 31,3 & 0,9 & 0,1 & 4,7 & 0,09 \\
\hline 2 & 80,7 & 30,3 & 2,2 & 1,0 & 3,9 & 0,11 \\
\hline 3 & 75,1 & 28,4 & 1,3 & 0,2 & 4,2 & 0,07 \\
\hline 4 & 123,0 & 33,8 & 6,1 & 2,4 & 6,2 & 0,06 \\
\hline 5 & 101,2 & 34,8 & 2,3 & 1,2 & 6,4 & 0,09 \\
\hline 6 & 77,6 & 34,4 & 4,9 & 1,4 & 5,9 & 0,09 \\
\hline 7 & 92,1 & 34,9 & 4,4 & 0,9 & 7,6 & 0,12 \\
\hline 8 & 91,3 & 34,9 & 3,0 & 1,0 & 6,6 & 0,12 \\
\hline 9 & 91,2 & 35,7 & 4,6 & 1,5 & 7,5 & 0,13 \\
\hline 10 & 106,4 & 35,2 & 4,9 & 1,0 & 7,7 & 0,13 \\
\hline 11 & 97,2 & 31,2 & 6,6 & 1,4 & 8,2 & 0,14 \\
\hline 12 & 107,3 & 38,5 & 5,7 & 2,4 & 8,0 & 0,13 \\
\hline 13 & 105,4 & 32,4 & 1,1 & 0,6 & 6,3 & 0,09 \\
\hline 14 & 99,8 & 33,6 & 6,0 & 0,3 & 4,1 & 0,07 \\
\hline 15 & 90,5 & 34,6 & 3,1 & 1,1 & 4,0 & 0,08 \\
\hline 16 & 100,2 & 35,0 & 3,7 & 1,1 & 4,0 & 0,04 \\
\hline 17 & 87,7 & 28,5 & 1,1 & 1,1 & 4,6 & 0,07 \\
\hline 18 & 102,6 & 33,5 & 6,3 & 1,6 & 7,7 & 0,12 \\
\hline 19 & 100,1 & 33,1 & 2,8 & 0,2 & 4,1 & 0,10 \\
\hline 20 & 105,7 & 33,4 & 4,3 & 1,9 & 6,2 & 0,14 \\
\hline $\mathbf{A}$ & $\mathbf{9 6 , 6}$ & $\mathbf{3 3 , 4}$ & $\mathbf{3 , 8}$ & $\mathbf{1 , 1}$ & $\mathbf{5 , 9}$ & $\mathbf{0 , 1 0}$ \\
\hline $\mathbf{\delta}_{\mathbf{A}}$ & $\mathbf{2 , 5}$ & $\mathbf{0 , 5}$ & $\mathbf{0 , 4}$ & $\mathbf{0 , 1}$ & $\mathbf{0 , 4}$ & $\mathbf{0 , 0 1}$ \\
\hline
\end{tabular}

Notes: A, $\square_{\mathrm{A}}$ - Average index and error

\footnotetext{
$\square \mathrm{A}=\square \sqrt{N} \quad \square$ - standard deviation; $\mathrm{N}$ - total sample size
}

Based on the results of the analyzes carried out on 20 samples of bottom sediments, "table 1", of which there are 12 samples along the Ham Luong River (downstream of the Mekong River in Ben Tre province), conclusions can be drawn: 
1) The content of heavy metals in most sampling sites tends to increase as you get closer to the sea. This proves that the further downstream at the mouth of the river, the stronger the interaction between the river and the sea, leading to the accumulation of silt and accompanied by the deposition of heavy metals downstream of the Mekong River in Ben Tre province. In the aquatic environment, bottom sediments play an important role in the absorption of pollutants during their deposition in the composition of suspended sediments and in processes associated with the sorption of inorganic and organic substances.

In particular, for samples taken in small tributaries flowing into the Ham Luong River (samples 13-16), the content of heavy metals in the bottom sediments of the river is relatively higher than in the main river. This proves that, in addition to the input from the upper reaches of the river, the industrial activities of the local population also made a significant contribution to the accumulation of heavy metals in bottom sediments.

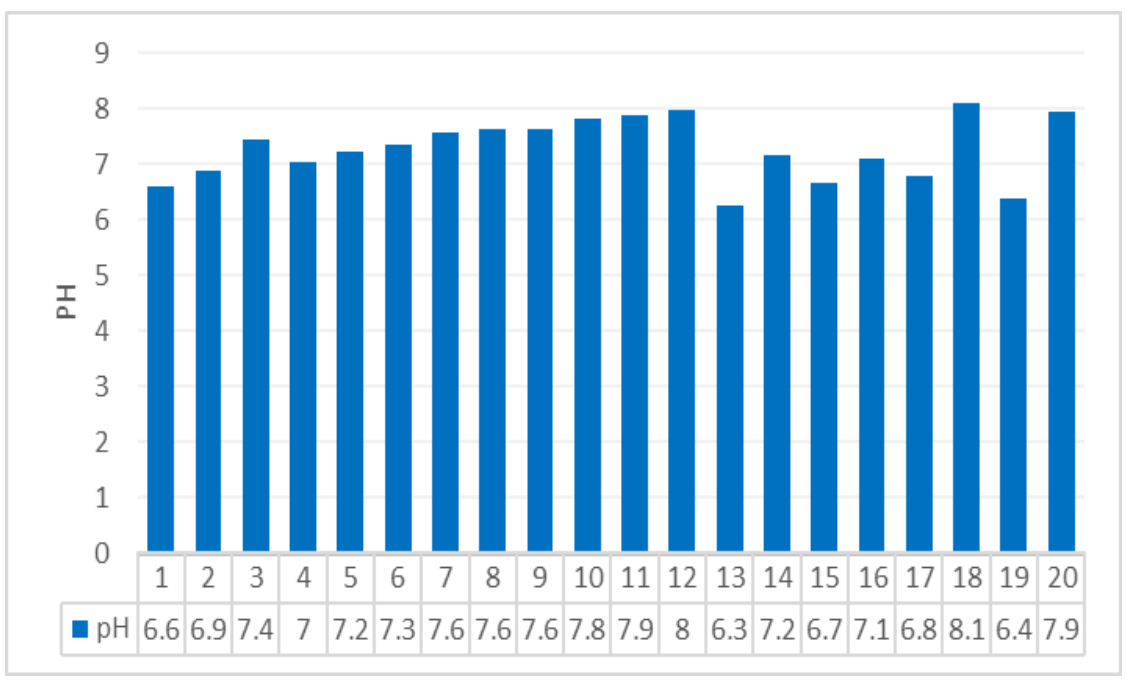

Fig. 4. The plot of pH changes in bottom sediments of the Lower Mekong River (Ben Tre)

(EC: Conductivity, $\mathrm{ms} / \mathrm{cm}$ )

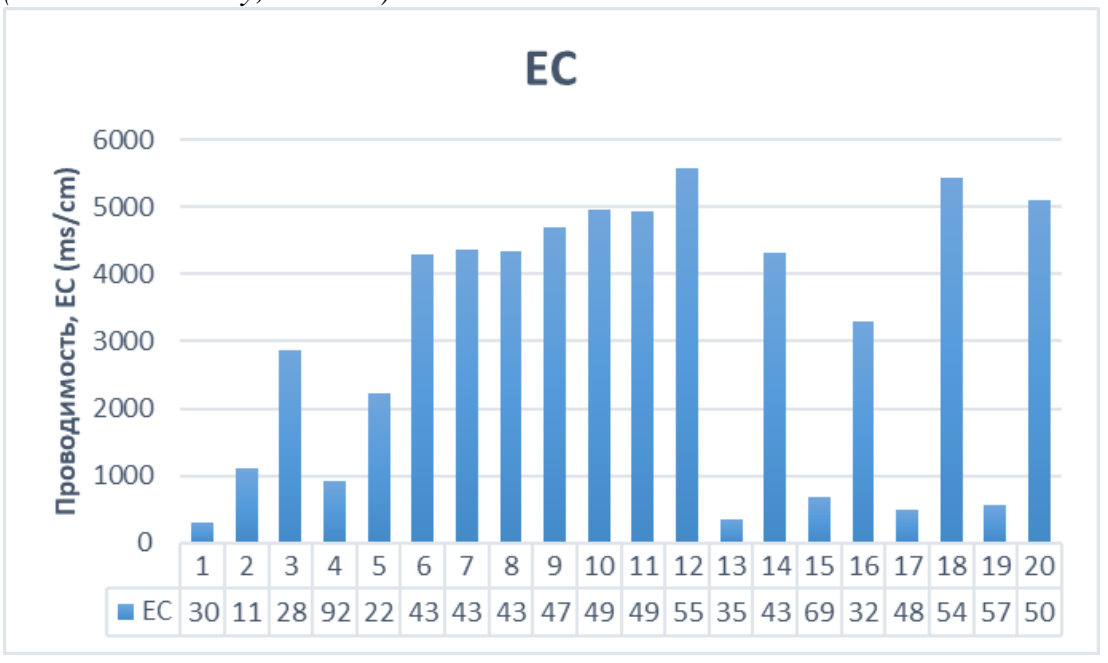

Fig. 5. A graph of the change in the EU of bottom sediments in the lower reaches of the Mekong River (Ben Tre)

2) Low $\mathrm{pH}$ values indicate the acidic environment of river bottom sediments. As can be seen from the plotted graphs (Fig. 4 and 5), the $\mathrm{pH}$ value is practically proportional to the electrical conductivity EC and the transparency of the mixture of seawater and fresh water, which has high acidity. According to the results of the analysis, it can be concluded that the $\mathrm{pH}$ value of bottom sediments gradually increases as it approaches the sea, which is similar to the dynamics of the content of heavy metals in water and bottom sediment sampling.

The index of change in conditions in the river delta was taken as a $\mathrm{pH}$ value that can be used to roughly estimate the actual assessment of the presence of trace elements in sediments along the length of the Mekong River. The statistical calculations took into account: the length of the river, and the planning of agricultural activities, water management taking into account the sustainable development of the Mekong region. 


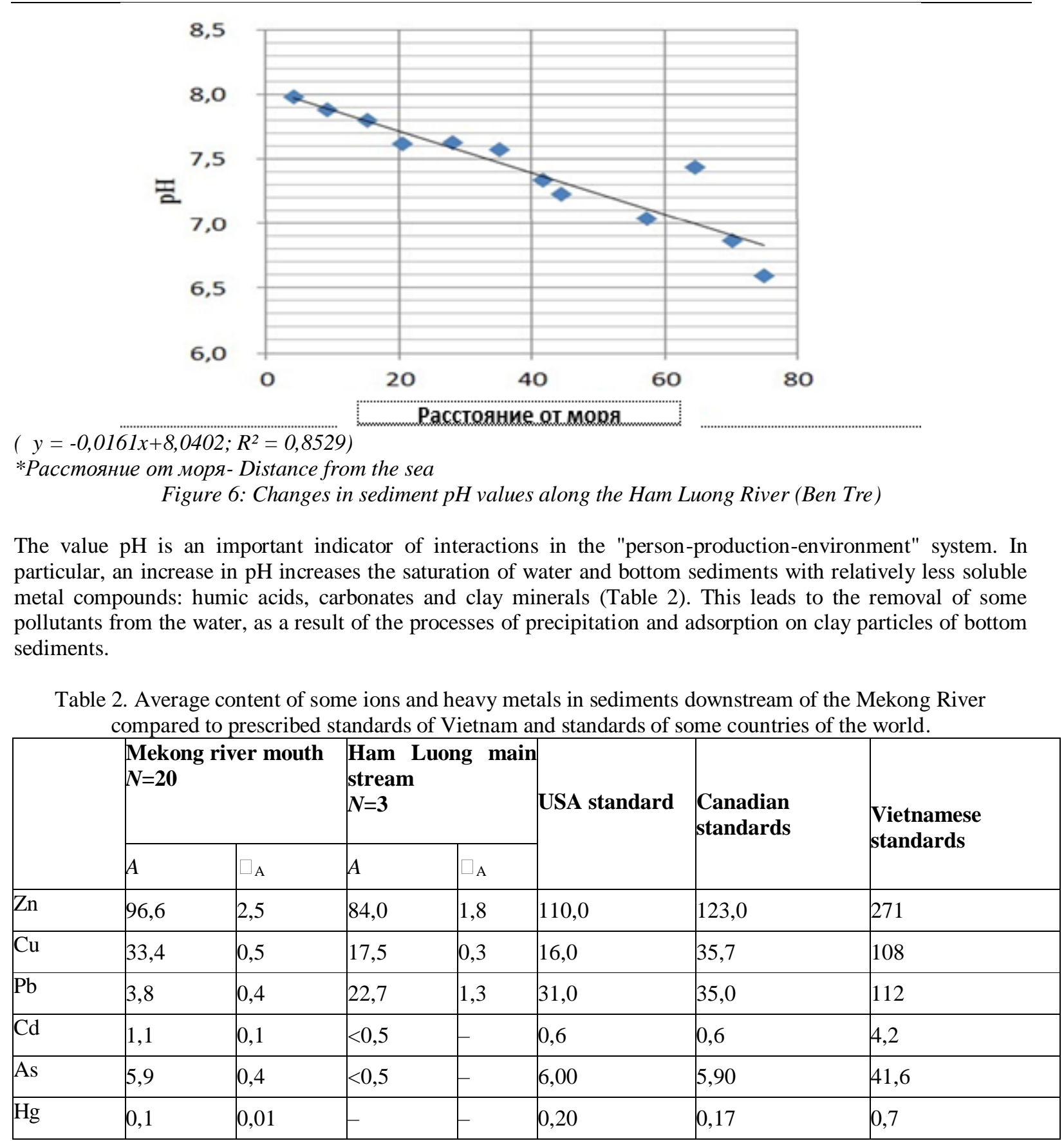

In line with Vietnam's National Technical Standards for Sediment Quality (QCVN 43: 2018 / BTNMT), the United States and Canada apply stricter guidelines for assessing and controlling sediment quality to protect aquatic life. Based on an analysis of 20 sediment samples from the Mekong estuary, it was found that the contents of $\mathrm{Zn}, \mathrm{Cu}, \mathrm{Cd}$, As and $\mathrm{Hg}$ (except $\mathrm{Pb}$ ) were approximately equal to the standards adopted in Vietnam. However, according to US and Canadian standards, some indicators significantly exceed the standards, especially for $\mathrm{Cu}$ and $\mathrm{Cd}$ "table 3 ".

The results showed that the values of the concentration of heavy metals in the bottom sediments of the mouth of the Mekon River obtained as a result of the studies carried out are consistent with the results of the studies of Houba (1995) [2]; Cenci \& Martin (2004) [4]; Defew (2007) [5]; Savichev O. G. (2012) [7]; Savichev O. G. and Phung Thai Duong (2016) [10].

It is safe to say that river mouths in the lower reaches of the Mekong River are the place of deposition of heavy metals that come from the upper sections of rivers and canals located in the Mekong River basin, and under the influence of anthropogenic activities, both economic and social. In general, sediment pollution tends to increase from the upstream to downstream of the Mekong River in Ben Tre province.

\section{Conclusion}


With the exception of lead, the heavy metal content of most of the sediment samples taken meets the Vietnamese national standards but exceeds the USA and Canadian heavy metal limits..

There is a danger to aquatic organisms and coastal ecosystems, especially due to the increased content of $\mathrm{Cu}$ and $\mathrm{Cd}$ in bottom sediments.

$\mathrm{pH}$ plays a special role in the "environment" system. The interaction between the river and the sea, the role of $\mathrm{pH}$ leads to water saturation, accumulation of sediments, deposition, absorption of heavy metals in bottom sediments. In general, the $\mathrm{pH}$ and heavy metal content gradually increase when going to sea. This proves that one of the sources of pollution is the updraft at the river mouth.

Small tributaries flowing into Ham Luong have a relatively higher content of heavy metals in bottom sediments than the main river, therefore the socio-economic activity of the local population is also one of the reasons influencing the content of heavy metals in bottom sediments in the lower reaches of the Mekong River.

\section{Recommendations}

In the lower reaches of the Mekong River at its mouth, river water enters the sea, while pollutants and heavy metals coming from upstream regions are deposited in bottom sediments in the lower reaches and at the river mouth. The results of the study show that the content of heavy metals such as $\mathrm{Cu}$ and $\mathrm{Cd}$ exceeds the permitted standard of the Vietnamese regulations.

To solve the problem of accumulation of heavy metals in bottom sediments at the mouth of the Mekong River, it is necessary:

- investigate the reasons for the influx of heavy metals into rivers in upstream areas, since the content of heavy metals in river tributaries is often higher than in the main river;

- study the availability and effectiveness of wastewater treatment at factories in the Mekong region prior to wastewater discharge into the river;

- estimate the amount of household waste discharged directly into the rivers - tributaries of the Mekong;

- estimate the amount of heavy metals input from agricultural land with diffuse runoff;

- to study fish farms, the availability of treatment facilities and their effectiveness;

- to identify illegal slavery and cattle breeding and evaluate its impact on the quality of water and bottom sediments;

- to study the influence of the quality of bottom sediments on the species composition and quality of fish products;

- develop recommendations for the management and protection of water and fish resources of the Mekong River in Ben Tre province.

\section{References}

1. GOST 17.1.5.01-80 (1984), "State standard of the USSR Union. Protection of Nature. Hydrosphere. General requirements for sampling of bottom sediments of water bodies for analysis for contamination", $5 c$.

2. Houba V. J. G., Van der Lee J. J., Novozamsky I (1995), "Soil analysis procedures, other procedures. (Soil and plant analysis, part 5b)", Department of Soil Science and Plant Nutrition, Wageningen Agricultural University.

3. Mikhailov VN (1997), "Hydrological processes in river mouths", Moscow: Moscow State University, $172 \mathrm{p}$.

4. Cenci R. M, Martin J. M (2004), “Concentration and fate of trace metals in Mekong River Delta", Science of the total Environment, No. 332, pp. 167-182.

5. Defew L. H, Mair J. M, Guzman H. M (2007), “An assessment of metal contamination in mangrove sediments and leaves from Punta Mala Bay, Pacific Panama”, Marine Pollution Bulletin, No. 50, p. 547 552 .

6. Pham Thi Nga, Le Van Duc, Nguyen Duy Duyen, Le Viet Thanh (2009), “Assessment of contamination of the deposition of heavy metals in sediments of the Gulf of Da Nang”, Geological journal ,No. 315 . Tr. 12-20.

7. Savichev OG (2012), "Technique of ecological and geochemical research",

8. Tomsk University Press, 183c.

9. Nguyen Van Khan, Pham Van Hiep (2012), "Studies on the Accumulation of Cadmium (Cd) and Lead (Pb) Deposits at the Da Nang Estuary," Journal of Science and Technology, No1, pp. 83-89.

10. Savichev OG, Phung Thai Duong (2015), "Zonal patterns of changes in the chemical composition of river sediments in Siberia and the conditions for its formation", Bulletin of the Tomsk Polytechnic University, No.1, p. 157-161.

11. Savichev OG, Phung Thai Duong (2016), "Ecological and geochemical state of surface waters and bottom sediments in the Mekong delta (Vietnam)", Bulletin of Tomsk State University, No.388, p. 246252. 
Glazunova Irina Viktorovna ${ }^{1}$, Karpenko Nina Petrovna ${ }^{2}$, Nguyen Thi Thuy Nhung ${ }^{3}$, Natalia V. Lagutina $^{4}$, Barsukova Maria Vasilievna ${ }^{5}$

12. Department of Agriculture and Rural Development, "Ben Tre Province 2018 Planning", 2019.

13. Glazunova I. V., Barsukova M. V. et al. - assessment of anthropogenic load on a water object. Natural and technical Sciences. - Moscow: publishing house: Sputnik+publishing house, LLC.-No. 11 - 2018 Pp. 123-128.

14. Glazunova I. V., Karpenko N. P. - management of land and water resources to reduce river pollution based on expert assessments of the effectiveness of environmental Measures. Scientific and practical journal "nature management".-Moscow: RGAU - MSHA named after K. A. Timiryazev-2019. - no. 4. Pp. 102-108.

15. Bakshtanin a.m., Ratkovich L. D. Markin a.m., Glazunova I. V., and others. Under the General editorship of L. D. Ratkovich - Textbook "Water Management systems and water use". Moscow: INFRA-M LLC2019. $-452 \mathrm{p}$.

16. 15. Efimov O.E., Kondratenko L., Barsukova M., Philippova A. Heavy metais in sediments of the Vasygan river (Russian Federation), chemical compassion and environmentai risk Asian Journal of Water, Environment and Pollution. 2020. T. 1. № 2. C. 81-89. 